\title{
Screening for disability in the inner city
}

\author{
DONALD L. PATRICK, SARAH C. DARBY, STEPHEN GREEN, GEOFFREY \\ HORTON, DAVID LOCKER, AND RICHARD D. WIGGINS \\ From the Department of Community Medicine, St. Thomas's Hospital Medical School, London
}

\begin{abstract}
SUMMARY A $10 \%$ sample of private households on the electoral register of the London Borough of Lambeth was screened for disabled persons aged 16 and over, using a postal questionnaire. After three mailings and individual follow-up of non-responders, $87 \%$ of the sample households returned questionnaires. Disability was defined in the screening questionnaire as functional limitations or activity restrictions consequent upon disease or impairment. The overall point prevalence of disability was estimated at $\mathbf{1 5 . 4 \%}$ and the most frequently reported impairments were those of the sense organs, bones, central nervous, circulatory, and respiratory systems. Hearing difficulties were the single most frequently reported functional limitation. A log-linear modelling procedure identified age, marital status, and working status as the factors most strongly associated with disability for both men and women. In addition, men aged 50-64 and not working, and men in manual occupations and living alone, were more likely to report disability. These findings indicate that some population groups are disabled by functional limitations and activity restrictions not included in official criteria for identification and assessment. These criteria might be broadened, and services planned for those population groups with higher rates of reported disability.
\end{abstract}

More than a decade ago, Bennett $e t$ al $^{1}$ conducted a two-stage prevalence survey of disability among those aged 15 and over living in North Lambeth. The authors reported prevalence estimates of $6.5 \%$ for men and $8 \cdot 1 \%$ for women. At the same time, the Office of Population Censuses and Surveys (OPCS) administered a two-stage postal and interview survey on a substantial national sample and later published comprehensive estimates of the numbers of handicapped and impaired people, and details of the nature of their impairments and their needs. ${ }^{2}$ Following this model two-stage OPCS survey, a large number of local authorities conducted similar prevalence studies to implement the 1970 Chronically Sick and Disabled Persons Act. The OPCS and local authority surveys have estimated that $4-8 \%$ of the population are physically impaired and of these between one-third and one-half are 'handicapped' or experience significant disadvantage from their impairments. The findings as well as the methodological weaknesses and difficulties in the local authority surveys have recently been reviewed. ${ }^{3}$ One persistent difficulty is the wide variety of definitions and measures of disability used in the various studies. Standardisation in concepts, operational definitions, and classification has proved difficult.
The World Health Organisation (WHO) has recently published a trial classification of impairment, disability, and handicap to supplement the International Classification of Diseases (ICD). ${ }^{4}$ Developed over the last decade, this classification system defines impairment as any loss or abnormality of psychological, physiological, or anatomical structure or function; disability as any restriction or lack (resulting from an impairment) of ability to perform an activity in the manner or within the range considered normal for a human being; and handicap as a disadvantage for a given individual, resulting from impairment or a disability, that limits or prevents the fulfilment of a role that is normal (depending on age, sex, and social and cultural factors) for that individual. The most important feature of this system is that it explicitly incorporates both the directly observable behavioural component and the less observable or subjective value component of most operational definitions of health and illness. ${ }^{6}$ No study has yet been conducted to implement the WHO definitions or classification system.

A long-term programme of research has begun at St. Thomas's Hospital Medical School into impairment, disability, and handicap in the inner city. As the first phase in the investigation, a single-stage 
postal survey was conducted in the London Borough of Lambeth to identify impaired and disabled persons living at home. The aim was to estimate the prevalence of impairments and disabilities in an urban community and to develop a model of the factors most strongly associated with disability. While most prevalence studies have reported the sociodemographic characteristics of their disabled sample, a multifactor description or model has not yet appeared. In addition, the development of an effective postal screen to identify the disabled was desired because of the obvious cost advantages over a multistage postal and face-to-face interview survey. ${ }^{7}$ Information from this study also facilitates planning of urban services by identifying those subgroups in the adult population most likely to require services or benefits.

\section{Method}

THE SCREENING QUESTIONNAIRE

Based on the developing WHO definitions and the extensive previous studies conducted in Britain and North America, a postal questionnaire to screen for persons in Lambeth with major impairments, functional limitations, and activity restrictions was devised, piloted, and evaluated. ${ }^{\mathbf{B}}$ The questionnaire consisted of 25 screening items, a section on illness conditions causing disability, and household information. The disability items fell into four broad categories:

(1) Ambulation and mobility-walking, negotiating stairs, going outside the house, crossing the road, travelling on bus or train;

(2) Body care and movement-getting in and out of bed or chair, dressing, kneeling or bending, bathing, holding or gripping, controlling bowels or bladder, toileting;

(3) Sensory-motor-giddiness or fits, frequent falls, weakness or paralysis of extremities, stroke, visual difficulties, hearing difficulties, loss of extremity; and

(4) Social activity - limitation because of illness in working at all, doing the job of choice, doing housework, visiting family or friends, or engaging in other social activities.

Respondents also described the major illnesses or disabling conditions for any household member reported to have a functional limitation or activity restriction.

Household information included the sex, year of birth, marital status and current employment status of each member of the household. To obtain a proxy measure for the social class of household members, four questions were asked concerning the current or main lifetime occupation of the head of the household during his or her working life. This enabled stratification to be carried out according to the Registrar General's Classification of Occupations.

\section{DEFINITION OF DISABILITY}

Respondents were classified as 'disabled' if they reported difficulty with one or more of (a) the ambulation, mobility, body care, or movement items, except constipation or stress incontinence alone; (b) the sensory-motor items except giddiness when no associated illness condition was reported; and/or (c) the social activity items, except limitation in working at all or doing the job of choice where the respondent was over retirement age.

\section{CODING OF IMPAIRMENTS}

Using the $I C D$ classification (8th revision), ${ }^{9}$ a medically qualified member of the study team coded the number ot illness conditions reported for each respondent, the main disabling condition and, for those reporting three or more conditions, the two conditions which he judged to be most closely associated with the reported pattern of disability.

\section{SA M P LE}

The aim of the sample design was to achieve a random sample of disabled and non-disabled individuals from the target population of all persons aged 16 and over living in private households in the borough of Lambeth at the beginning of 1978. In an attempt to identify households directly a 'same-surname-address' sample, where surnames act as a tag to identify households, was selected. The 1977 Lambeth electoral register, updated by the list of additions and deletions available after the autumn canvass of potential electors, was used as the sampling frame. A one-in-10 sample of surnames on the register was selected, using the 'firsting' principle developed by the OPCS, whereby a surname is chosen only if it is the first one within a surname sequence on the register. ${ }^{10}$ When the questionnaires were returned, a count was taken of the surnames listed in the household information section, enabling us to calculate the relative chance of a household appearing in the sample. This 'weighting' adjustment was then used to calculate the prevalence estimates from the sample responses to the survey according to a method of ratio estimation proposed by Cochran. ${ }^{11}$

MODELLING PROCEDURE

Causal hypotheses using factors which may be either a cause or a consequence of disability could not be tested in this cross-sectional study. However, the set of factors associated most strongly with reported disability could be determined by a modelling 
procedure. Logit analysis was used to identify the most parsimonious set of factors which best described those population groups most frequently reporting disability. ${ }^{12}$

\section{COMPARISON OF PREVALENCE RATES}

Differences in the prevalence estimates obtained by various studies can be attributed to varying definitions, methods, and analyses, or to an actual increase or decrease in reported disability. An absolute change cannot be detected using a single point-prevalence survey, but it is possible to examine the differences in definition and method by comparing results obtained in the present study with those from studies using similar or different approaches. The 1968 Lambeth survey and the 1969 national (OPCS) survey were chosen for comparison of the items used to detect disability and the wording of the questionnaire. ${ }^{12}$

\section{Results}

\section{RESPONSE}

The total sample set consisted of 11659 named-person addresses. After an initial mailing and two reminders, $74.1 \%$ of the eligible returns had been received. Medical students visited all addresses from which there had been no reply after the third mailing and for which questionnaires had not been returned by the Post Office. This follow-up yielded an additional $12.5 \%$ replies, bringing the final response rate to $86.6 \%$. Of the non-productive addresses, $5.2 \%$ refused, $2.9 \%$ could not be contacted, and $5 \cdot 1 \%$ were not obtained after one visit to the address by the medical students. Only $0 \cdot 2 \%$ of the replies contained information too inadequate to use in the analysis of the results. Details of the survey response are to be published separately (Department of Community Medicine, St. Thomas's Hospital, unpublished observations). In total, information was obtained from 8735 households which contained 23600 persons. Of these, 18745 or $79.4 \%$ were aged 16 or over and eligible for classification by disability status.

PREVALENCE OF DISABILITY IN SAMPLE

Table 1 shows that for each of the four categories of disability and for persons reporting one or more items, the prevalence of disability increased with age for both sexes. Women consistently reported disability more frequently than men for all age groups and item categories.

The most frequently reported functional limitations were hearing difficulties $(4 \cdot 5 \%)$. weakness and paralysis $(3 \cdot 3 \%)$, and difficulty seeing newspaper print, even with glasses $(2 \cdot 9 \%)$. The social activity restrictions most frequently reported included difficulty with housework $(3 \cdot 8 \%)$ and difficulty in visiting family and friends $(3 \cdot 4 \%)$. As might be expected, women (5.9\%) more frequently reported housework difficulties than men $(1 \cdot 5 \%)$. Other frequently reported limitations included kneeling and bending without help (3.5\%) and travelling on a bus or train $(4 \cdot 1 \%)$.

The major disabling illness conditions reported by disabled men and women are shown in the Figure. Sensory conditions were most prevalent for both sexes $(28 \cdot 3 \%)$. Women reported significantly more

Table 1 Proportion of sample by category of items on screening questionnaire

\begin{tabular}{|c|c|c|c|c|c|c|c|}
\hline \multirow[b]{2}{*}{ Category } & \multirow[b]{2}{*}{ Sex } & \multicolumn{5}{|c|}{ Age groups (years) } & \multirow[b]{2}{*}{ All ages } \\
\hline & & $16-29$ & $30-49$ & $50-64$ & $65-74$ & $\geqslant 75$ & \\
\hline Ambulation and mobility & $\begin{array}{l}\mathbf{M} \\
\mathbf{F}\end{array}$ & $\begin{array}{l}0.1 \\
0.1\end{array}$ & $\begin{array}{l}0.4 \\
0.9\end{array}$ & $\begin{array}{l}2 \cdot 3 \\
3 \cdot 3\end{array}$ & $\begin{array}{l}5 \cdot 1 \\
8 \cdot 4\end{array}$ & $\begin{array}{l}11.6 \\
22.1\end{array}$ & $\begin{array}{l}1.8 \\
4.3\end{array}$ \\
\hline Body care and movement & $\begin{array}{l}\mathbf{M} \\
\mathbf{F}\end{array}$ & $\begin{array}{l}0 \cdot 3 \\
0 \cdot 5\end{array}$ & $\begin{array}{l}1.3 \\
2.0\end{array}$ & $\begin{array}{l}3.7 \\
4.9\end{array}$ & $\begin{array}{r}9 \cdot 3 \\
13 \cdot 4\end{array}$ & $\begin{array}{l}22 \cdot 2 \\
33 \cdot 8\end{array}$ & $\begin{array}{l}3.3 \\
6.8\end{array}$ \\
\hline Sensory-motor limitation & $\begin{array}{l}\mathbf{M} \\
\mathbf{F}\end{array}$ & $\begin{array}{l}1.4 \\
1.5\end{array}$ & $\begin{array}{l}3 \cdot 1 \\
5 \cdot 3\end{array}$ & $\begin{array}{l}11.0 \\
11.8\end{array}$ & $\begin{array}{l}21.6 \\
22.7\end{array}$ & $\begin{array}{l}36 \cdot 1 \\
48 \cdot 2\end{array}$ & $\begin{array}{r}8 \cdot 0 \\
12 \cdot 1\end{array}$ \\
\hline Social activity restriction & $\begin{array}{l}\mathbf{M} \\
\mathbf{F}\end{array}$ & $\begin{array}{l}1.6 \\
1.8\end{array}$ & $\begin{array}{l}3 \cdot 8 \\
5 \cdot 5\end{array}$ & $\begin{array}{r}10.6 \\
9.8\end{array}$ & $\begin{array}{l}11.7 \\
16.6\end{array}$ & $\begin{array}{l}17.9 \\
34.7\end{array}$ & $\begin{array}{l}6.2 \\
9.7\end{array}$ \\
\hline Responding to one or more items & $\begin{array}{l}\mathbf{M} \\
\mathbf{F}\end{array}$ & $\begin{array}{l}2 \cdot 0 \\
2 \cdot 3\end{array}$ & $\begin{array}{l}4.6 \\
7.6\end{array}$ & $\begin{array}{l}15 \cdot 5 \\
16 \cdot 3\end{array}$ & $\begin{array}{l}25.5 \\
30 \cdot 5\end{array}$ & $\begin{array}{l}42.9 \\
58 \cdot 6\end{array}$ & $\begin{array}{l}10.4 \\
15.9\end{array}$ \\
\hline Number of persons in age group & $\begin{array}{l}\mathbf{M} \\
\mathbf{F}\end{array}$ & $\begin{array}{l}2856 \\
2925\end{array}$ & $\begin{array}{l}2557 \\
2656\end{array}$ & $\begin{array}{l}1938 \\
2144\end{array}$ & $\begin{array}{r}958 \\
1257\end{array}$ & $\begin{array}{r}441 \\
1008\end{array}$ & $\begin{array}{l}8750 \\
9990\end{array}$ \\
\hline
\end{tabular}




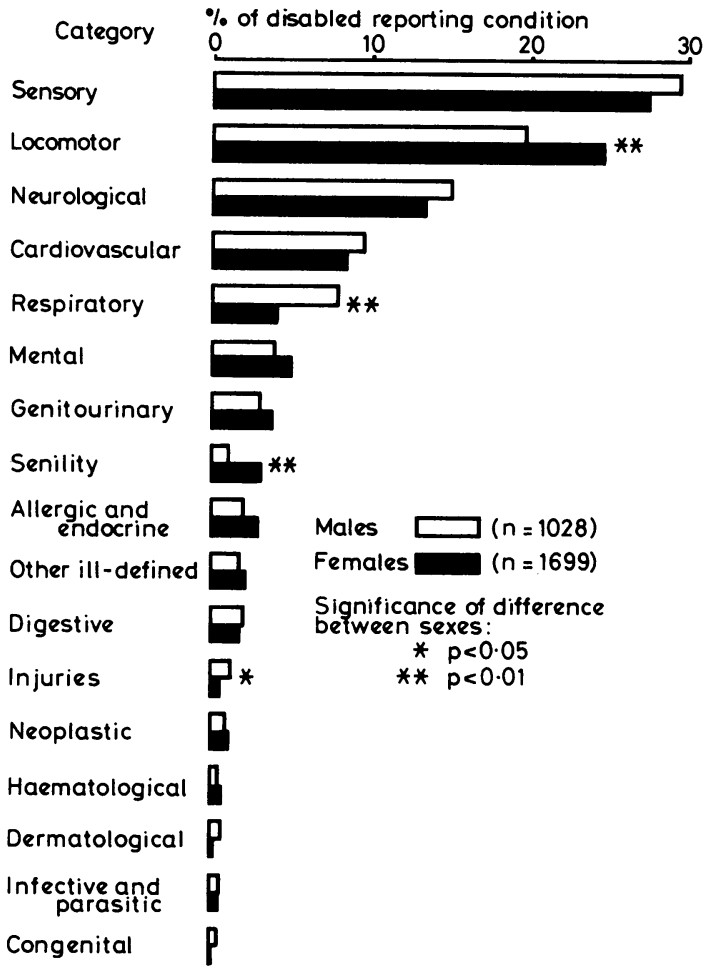

Figure Percentage of disabled respondents by sex and category of main disabling condition.

locomotor conditions, mainly arthritic disease, and more conditions associated with senility. Men reported significantly more respiratory conditions and more injuries.

PREVALENCE OF DISABILITY IN LAMBETH The estimated prevalence of disability in Lambeth households by age and sex is shown in Table 2 . It is estimated that $17.9 \%$ of women and $12.5 \%$ of men living at home in Lambeth have some functional limitation or activity restriction. These prevalence estimates have been applied to the 1977 Greater London Council population projections for Lambeth. There are 30-32 000 persons aged 16 or over living at home in the borough $(95 \%$ confidence interval) who have a functional limitation or activity restriction of the kind listed in the screening questionnaire.

FACTORS ASSOCIATED WITH DISABILITY In Table 3 the disabled are compared with the non-disabled by age, sex, marital status, employment status, social class of the household, and method of questionnaire collection, that is, whether it was
Table 2 Estimated prevalence of disabled persons aged 16 or over living at home in Lambeth by age and sex

\begin{tabular}{lrrrrrr}
\hline \multirow{2}{*}{$\begin{array}{l}\text { Age groups } \\
\text { (years) }\end{array}$} & \multicolumn{3}{l}{ Estimated per cent $\dagger$ and (numbers) $\ddagger$} \\
\cline { 2 - 7 } & Males & \multicolumn{3}{c}{ Females } & \multicolumn{2}{c}{ All persons } \\
\hline 16 & $3 \cdot 0$ & $(1000)$ & $3 \cdot 4$ & $(1100)$ & $3 \cdot 2$ & $(2100)$ \\
$30-49$ & $6 \cdot 1$ & $(2100)$ & $8 \cdot 6$ & $(2900)$ & $7 \cdot 4$ & $(5000)$ \\
$50-64$ & $17 \cdot 9$ & $(4200)$ & $18 \cdot 2$ & $(4700)$ & $18 \cdot 1$ & $(8900)$ \\
$65-74$ & $27 \cdot 2$ & $(2900)$ & $32 \cdot 4$ & $(4500)$ & $30 \cdot 1$ & $(7400)$ \\
$\geqslant 75$ & $43 \cdot 3$ & $(1800)$ & $60 \cdot 6$ & $(5700)$ & $55 \cdot 1$ & $(7500)$ \\
All ages & $12 \cdot 5$ & $(12000)$ & $17 \cdot 9$ & $(18900)$ & $15 \cdot 4 \dagger$ & $(30900)$ \\
\hline
\end{tabular}

†Standard error of estimate $=0 \cdot 18$.

¥Estimates for 1977 rounded to the nearest hundred using GLC population projection figures for Lambeth.

returned by post or collected by medical students. A significantly higher proportion of the disabled than of the non-disabled were aged 65 or over and were women. The disabled were also more likely to be widowed, separated, or divorced, not working (of working age), living in households where the head of the household was or had been engaged in a manual occupation, and living alone. A significantly higher proportion of the disabled than of the non-disabled were identified during the earlier postal phase of the study.

Initial analysis using the modelling procedure suggested a strategy for fitting separate models for women and men using postal returns only. For women, age, marital status, and working status were important factors associated with disability: women were more likely to report disability if they were older, not married, and not working (of working age). For men, these three factors as well as working in a manual occupation or living alone were associated more frequently with reported disability. In addition,

Table 3 Comparison of the disabled and non-disabled on seven descriptive factors

\begin{tabular}{|c|c|c|c|}
\hline & $\begin{array}{l}\text { Per cent of } \\
\text { disabled }\end{array}$ & $\begin{array}{l}\text { Per cent of } \\
\text { non-disabled }\end{array}$ & \\
\hline Factor & $(n=2727)$ & $(n=16013)$ & $p^{\dagger}$ \\
\hline \multicolumn{4}{|l|}{ Age } \\
\hline (65 and over) & $53 \cdot 2$ & $13 \cdot 8$ & $<0.01$ \\
\hline Sex (women) & $62 \cdot 3$ & $51 \cdot 8$ & $<0.01$ \\
\hline \multicolumn{4}{|l|}{$\begin{array}{l}\text { Marital status } \\
\text { (widowed, } \\
\text { separated }\end{array}$} \\
\hline \multicolumn{4}{|l|}{$\begin{array}{l}\text { Employment } \\
\text { status }\end{array}$} \\
\hline (not working) & $44 \cdot 8 \ddagger$ & $24 \cdot 4^{*}$ & $<0.01$ \\
\hline \multicolumn{4}{|l|}{$\begin{array}{l}\text { Social class } \\
\text { (manual }\end{array}$} \\
\hline household) & $53 \cdot 5$ & $51 \cdot 1$ & $<0.05$ \\
\hline \multicolumn{4}{|l|}{ Household size } \\
\hline $\begin{array}{l}\text { (iiving alone) } \\
\text { Method (postal) }\end{array}$ & $\begin{array}{l}24 \cdot 2 \\
87 \cdot 3\end{array}$ & $\begin{array}{r}8 \cdot 7 \\
82 \cdot 4\end{array}$ & $\begin{array}{l}<0.01 \\
<0.01\end{array}$ \\
\hline
\end{tabular}


joint effects or interactions between age and employment status, and social class and household size, were included in the model for men. The rate of disability steadily increased with age for men, but there was a differential pattern of association with respect to working status: the odds of being reported disabled for men aged 50-64 and not working were much higher than for men in any other age group. In addition, men working in a manual occupation and living alone were more frequently reported disabled.

COMPARISON WITH 1968 LAMBETH SURVEY AND 1969 NATIONAL SURVEY

Table 4 shows the proportion of males and females responding to those disability items which were used in both the 1968 and the 1978 Lambeth health surveys. A higher proportion of both males and females reported disability in 1978 for all items except 'other daily activities' where the reverse trend was noted for males. Males also reported more disability in 1968 when one or more of the disability items were considered. Table 5 shows the comparison between the prevalence estimates from the 1969 national sample survey and the 1978 Lambeth survey when using comparable definitions of disability. Differences between the two estimates increase with the age categories compared, although the overall estimates are nearly identical.

Table 4 Comparison of 1968 and 1978 Lambeth surveys: proportion of males and females aged 15 and over responding to selected disability items

\begin{tabular}{|c|c|c|c|c|}
\hline \multirow[b]{2}{*}{ Item } & & \multirow{2}{*}{$\frac{1968}{\%}$} & \multirow{2}{*}{$\frac{1978}{\%}$} & \multirow[b]{2}{*}{$p \dagger$} \\
\hline & & & & \\
\hline $\begin{array}{l}\text { Getting in and out of bed } \\
\text { or chair }\end{array}$ & $\begin{array}{l}\mathbf{M} \\
\mathbf{F}\end{array}$ & $\begin{array}{l}0.3 \\
0.7\end{array}$ & $\begin{array}{l}0.9 \\
1.8\end{array}$ & $\begin{array}{l}<0.01 \\
<0.01\end{array}$ \\
\hline Dressing or undressing & $\begin{array}{l}\mathbf{M} \\
\mathbf{F}\end{array}$ & $\begin{array}{l}0.4 \\
0.7\end{array}$ & $\begin{array}{l}0 \cdot 8 \\
1 \cdot 5\end{array}$ & $\begin{array}{l}<0.01 \\
<0.01\end{array}$ \\
\hline Going up and down stairs & $\begin{array}{l}\mathbf{M} \\
\mathbf{F}\end{array}$ & $\begin{array}{l}1 \cdot 1 \\
2 \cdot 7\end{array}$ & $\begin{array}{l}1 \cdot 8 \\
4 \cdot 2\end{array}$ & $\begin{array}{l}<0.01 \\
<0.01\end{array}$ \\
\hline Going out in the street & $\begin{array}{l}\mathbf{M} \\
\mathbf{F}\end{array}$ & $\begin{array}{l}1 \cdot 2 \\
3 \cdot 0\end{array}$ & $\begin{array}{l}1 \cdot 8 \\
5 \cdot 1\end{array}$ & $\begin{array}{l}<0.01 \\
<0.01\end{array}$ \\
\hline Limited in daily activities & $\begin{array}{l}\mathbf{M} \\
\mathbf{F}\end{array}$ & $\begin{array}{l}6 \cdot 0 \\
8 \cdot 1\end{array}$ & $\begin{array}{l}4 \cdot 6 \\
8 \cdot 4\end{array}$ & $\begin{array}{l}<0.01 \\
\text { NS }\end{array}$ \\
\hline $\begin{array}{l}\text { One or more disability } \\
\text { items reported }\end{array}$ & $\begin{array}{l}\mathbf{M} \\
\mathbf{F}\end{array}$ & $\begin{array}{l}6 \cdot 5 \\
8 \cdot 1\end{array}$ & $\begin{array}{r}5 \cdot 3 \\
10 \cdot 0\end{array}$ & $\begin{array}{l}<0.01 \\
<0.01\end{array}$ \\
\hline No. of persons & $\begin{array}{l}\mathbf{M} \\
\mathbf{F}\end{array}$ & $\begin{array}{l}6633 \\
7270\end{array}$ & $\begin{array}{r}8901 \\
10154\end{array}$ & \\
\hline
\end{tabular}

$+\chi^{2}$ test.
Table 5 Comparison of prevalence estimates from Lambeth (1978) and national sample (1969) surveys

\begin{tabular}{|c|c|c|c|c|}
\hline $\begin{array}{l}\text { Age group } \\
\text { (years) }\end{array}$ & Sex & $\frac{1969}{\%}$ & $\frac{1978}{\%}$ & $p^{\dagger}$ \\
\hline $16-29$ & $\begin{array}{l}\mathbf{M} \\
\mathbf{F}\end{array}$ & $\begin{array}{l}1.00 \\
0.79\end{array}$ & $\begin{array}{l}0.8 \\
0.8\end{array}$ & $\begin{array}{l}\text { NS } \\
\text { NS }\end{array}$ \\
\hline $30-49$ & $\begin{array}{l}\mathbf{M} \\
\mathbf{F}\end{array}$ & $\begin{array}{l}3.02 \\
2.56\end{array}$ & $\begin{array}{l}2.5 \\
3.7\end{array}$ & $\begin{array}{l}\text { NS } \\
<0.01\end{array}$ \\
\hline $50-64$ & $\begin{array}{l}\mathbf{M} \\
\mathbf{F}\end{array}$ & $\begin{array}{l}8.56 \\
8.46\end{array}$ & $\begin{array}{l}8 \cdot 0 \\
8 \cdot 3\end{array}$ & $\begin{array}{l}\text { NS } \\
\text { NS }\end{array}$ \\
\hline $65-74$ & $\begin{array}{l}\mathbf{M} \\
\mathbf{F}\end{array}$ & $\begin{array}{l}21 \cdot 14 \\
22 \cdot 71\end{array}$ & $\begin{array}{l}13 \cdot 6 \\
17 \cdot 5\end{array}$ & $\begin{array}{l}<0.01 \\
<0.01\end{array}$ \\
\hline$\geqslant 75$ & $\begin{array}{l}\mathbf{M} \\
\mathbf{F}\end{array}$ & $\begin{array}{l}31 \cdot 62 \\
40.90\end{array}$ & $\begin{array}{l}25 \cdot 6 \\
42 \cdot 2\end{array}$ & $\begin{array}{l}<0.05 \\
\text { NS }\end{array}$ \\
\hline All ages & $\begin{array}{l}\mathbf{M} \\
\mathbf{F}\end{array}$ & $\begin{array}{l}6 \cdot 67 \\
8 \cdot 82\end{array}$ & $\begin{array}{l}5 \cdot 9 \\
9 \cdot 7\end{array}$ & $\begin{array}{l}<0.01 \\
<0.01\end{array}$ \\
\hline Total & & $7 \cdot 80$ & 7.9 & NS \\
\hline No. of persons & & $(\mathrm{n}=187311)$ & $(n=18740)$ & \\
\hline
\end{tabular}

${ }^{+} \chi^{2}$ test.

\section{Discussion}

The definition of disability used in this study included a wider range and number of functional limitations and activity restrictions than has been used previously. Eleven of the 25 items, however, were similar to those used in the 1969 national sample survey, which produced prevalence estimates of $6.7 \%$ for males, $8 \cdot 8 \%$ for females, and $7 \cdot 8 \%$ for all persons. Prevalence estimates for the Lambeth sample based on the same 11 items were $5.9 \%$ for males, $\mathbf{9 . 7 \%}$ for females, and $\mathbf{7 . 9 \%}$ for all persons. It would appear that the broad 25-item definition, including limitations or restrictions not in the 1.969 national or subsequent local authority surveys, is primarily responsible for the two-fold increase in prevalence. Sensory-motor items such as frequent falls, and occupation-related items such as difficulty doing job of choice or housework, significantly increase reported disability.

The results of this study indicate that a significant number of additional people may be identified as disabled by functional limitations and activity restrictions not used by the local authorities in their surveys to assess the numbers and needs of disabled persons. Some local authorities identify and assess handicapped persons using criteria based on ambulation, mobility, and self-care items alone. This 
study raises the question whether identification criteria should be broadened to include some of our additional disability items.

Comparing the response to specific items used in both the 1968 and 1978 Lambeth health surveys allowed an examintion of the effect of question wording on response. In 1968, the items were asked as questions about the capacity of respondents to perform activities of daily living, for example, 'can you get in and out of bed by yourself'?, or 'can you dress or undress yourself? In 1978, the same questions were asked in terms of the performance or non-performance of activities because of illness, for example, 'do you have difficulty dressing or undressing without help'? Recent evidence suggests that this variation in wording may account for as much as $15-20 \%$ of under-reporting of illness-related dysfunction in population surveys. ${ }^{13}$ The significantly higher responses to the disability items obtained in 1978 support the importance of such an effect, particularly in view of the comparable findings between the national OPCS and the 1978 Lambeth surveys which used performance questions. As performance is more readily observable and objective than capacity, the questions on capacity might well be abandoned for measures of self-reported disability.

Our analyses of the factors associated with disability suggest that a number of groups in the urban population are more likely to report disability: persons who are older, not married, or not working and under retirement age, especially men aged 50-64, and older men in manual occupations but living alone. Such information can be used by the health and social service authorities to help plan services by identifying care groups using criteria other than age. For example, scarce manpower resources have to be rationed among different client groups, and the needs of the disabled aged under 16 and over 65 are believed to be so much greater than those in intermediate age groups that the latter have the lowest allocation of man hours in many health and social service departments. It could be argued that these persons, being of employable age, are a particularly important group. Persons who are unemployed, separated or divorced, or living alone need special consideration when health resources are being planned and allocated, and special efforts are required to identify the unmet needs of these groups.

The identification of new groups of disabled people is an important objective of tertiary prevention: screening, early diagnosis, and prescription of treatment, medical and social rehabilitation, and compensation. In planning services, estimating the quantity of services or benefits required, and allocating resources to different areas or client groups, it is essential to consider the factors known to be associated with disability. Identifying high-risk groups in prevalence studies such as the one reported here is an important first step in the determination of unmet need.

This study was sponsored by the St. Thomas's and King's Health District with funding by the Department of Health and Social Security and the Special Trustees of St. Thomas's Hospital. Members of the Department of Community Medicine have given us their advice and encouragement. We also thank all the administrative, fieldwork, clinical, coding, and computing assistants who worked with us in carrying out the innumerable tasks of a postal survey. To all the respondents of the borough of Lambeth, we are most grateful.

Reprints from Dr. Donald L. Patrick, Senior Lecturer and Head, Social Science Section, Department of Community Medicine, St. Thomas's Hospital Medical School, London SE1 7EH.

\section{References}

${ }^{1}$ Bennett AE, Garrad J, Halil T. Chronic disease and disability in the community: a prevalence study. $\mathrm{Br}$ Med $J$ 1970; iii: 762-4.

${ }^{2}$ Harris AI. Handicapped and impaired in Great Britain. Part I. London: HMSO, 1971.

${ }^{3}$ Knight R, Warren MD. Physically disabled people living at home: a study of numbers and needs. London: HMSO, 1978.

${ }^{4}$ Wood PHN. Classification of Impairments and Handicaps. Geneva: World Health Organisation, 1975.

${ }^{s}$ World Health Organisation. International Classification of Impairments, Disabilities and Handicaps. Geneva: WHO, 1980.

${ }^{6}$ Patrick DL, Bush JW, Chen MM. Toward an operational definition of health.J Health Soc Behav 1973; 14: 6-23.

${ }^{7}$ Dillman DA. Mail and Telephone Surveys. New York: John Wiley and Sons, 1978.

${ }^{8}$ Peach H, Green S, Locker D, Darby S, Patrick D. Evaluation of a postal screening questionnaire to identify the physically disabled. Int J Rehabil Med (in press).

${ }^{9}$ World Health Organisation. International Classification of Diseases, 8th revision. Geneva: WHO, 1967.

${ }^{10} \mathrm{Harris}$ AI, Head E. Sample surveys in local authority areas, revised edn. London: Social Survey Division, Office of Population Censuses and Surveys, 1974.

${ }^{11}$ Cochran WG. Sampling techniques, 2nd edn. London: John Wiley and Sons, 1962.

${ }^{12}$ Cox DR. The analysis of binary data. London: Methuen, 1971.

${ }^{13}$ Anderson JP, Bush JW, Berry CC. Performance versus capacity: a conflict in classifying function for health status measurement. Am J Public Health (in press). 